\title{
El arte en la publicidad. Tipologías del uso del arte visual en la comunicación comercial
}

Art in advertising.

Types of use of visual art in the commercial communication

\section{Olga Heredero Díaz}

Universidad Complutense de Madrid, España.

olga.heredero.diazQucm.es

\section{Miguel Ángel Chaves Martín}

Universidad Complutense de Madrid, España.

mchavesaucm.es

\section{Resumen}

La saturación publicitaria en un mercado globalizado altamente competitivo, en el que las diferencias funcionales entre los productos apenas existen, obliga a las marcas a innovar en la búsqueda de nuevas estrategias comunicativas que generen valor y engagement con el consumidor. En este sentido, la inclusión de referencias al arte visual en la comunicación comercial se propone como un modelo válido, fundamentado empíricamente en el "efecto de transfusión del arte". El objetivo de este artículo es la clasificación de la diversidad de formas que puede adoptar esta estrategia, que en base al modelo de Hjemslev, aplicado al estudio del significante del lenguaje publicitario mediante la dicotomía expresión/contenido, define once tipologías distintas, de las que se incluyen varios ejemplos.

\section{Palabras clave}

Publicidad, arte, clasificación, tipología, efecto de transfusión.

\begin{abstract}
Advertising saturation in a highly competitive globalized market, where functional differences among products barely exist, forces brands to innovate in the search of new communicative strategies that generate value and consumer engagement. In this respect, the inclusion of visual art references in commercial communications is proposed as a valid model, empirically founded in the phenomenon of "art infusion". The classification of the diversity of forms that this strategy can adopt is this article's objective, that based on Hjemslev's model applied to the study of the advertising language signifier through the expression/content dichotomy, defines eleven different typologies, including several examples.
\end{abstract}

\section{Key Words}

Advertising, art, classification, typology, art infusion. 


\section{Introducción}

En un escenario comunicacional en transformación, marcado por el impacto de las nuevas tecnologías en la sociedad y donde la globalización plantea tanto retos como oportunidades, la importancia de los activos intangibles ha ido creciendo a un ritmo vertiginoso. Entre ellos destaca la marca y su gestión, que hoy se consideran valores fundamentales en el entorno empresarial (Villafañe, 2001). Sin embargo, hasta hace apenas un par de décadas, el modelo empresarial imperante se basaba exclusivamente en las leyes de la oferta y la demanda y en la capacidad del mercado para lograr equilibrarlas (Muñoz, 2008). Un planteamiento que tenía su reflejo en la comunicación, en la que dominaban las estrategias orientadas a impactar al público con un mensaje unidireccional y masivo, derivadas en su mayoría de la teoría matemática de la información de Shannon y Weaver ${ }^{1}$.

Un enfoque muy alejado de la realidad actual, donde se manifiesta la transformación de la relación entre la empresa y sus públicos a través de una comunicación innovadora que permite su diferenciación (Costa, 2012). La razón principal reside en que los consumidores de hoy consideran la calidad y la funcionalidad de los productos como sobreentendidas, de forma que esperan algo más, "un valor añadido por el que el consumidor está dispuesto a pagar" (Bocigas, 2011: 53). Se redefine así un mercado de consumo con un nuevo protagonista, el prosumer ${ }^{2}$, un sujeto más exigente, más informado y más activo, que demanda excelencia -no solo calidad-, trato personalizado, variedad, accesibilidad e inmediatez a un precio razonable. Es además co-creador de los productos en la medida que éstos se diseñan en función de sus necesidades y deseos, y se muestra cada vez más escéptico hacia el discurso de la publicidad convencional (Ritzer y Jurgenson, 2010). Un consumidor multipantalla y multicanal que requiere una comunicación relevante, útil, que entretenga, emocione y con la que pueda implicarse (engagement).

Todo ello obliga a las marcas a buscar e identificar oportunidades de creación de valor percibido, lo que a su vez les exige una continua renovación de conocimientos y aptitudes para diferenciarse de sus competidores, transformándose en lo que se conoce como la "marca experiencia", definida por Alloza (2002) como "el conjunto de las experiencias positivas que el público tiene al relacionarse con la organización".
En consecuencia, es en este contexto publicitario altamente competitivo, caracterizado por la sobreexposición del público a la publicidad, en el que la inclusión de referencias al arte en la comunicación de las marcas se revela como una fórmula válida para añadir valor a las características funcionales de los productos (Cavalli, 2007). Una estrategia que se enmarca dentro de la tendencia creciente que apuesta por una publicidad desvinculada de la necesidad de destacar las características de los productos, obviando lo argumentativo y lo racional, para adoptar formas mucho más libres y, en cierto modo, más próximas al arte que a la vieja publicidad (López, 2007).

\section{Discusión teórica}

\subsection{La relación entre el arte y la publicidad}

La fusión entre arte y publicidad, para algunos bastante innovadora, en realidad, no lo es tanto. Ambas disciplinas iniciaron su relación allá por 1900 , cuando los artistas de las vanguardias vieron en la publicidad a través del cartel una alternativa para participar en la creación de un nuevo espacio urbano, en el que los productos se exhibían, incluso hasta invadir el espacio doméstico (González, 1997). Será a partir de entonces cuando el arte se involucre en la creación de la imagen de las marcas de la incipiente sociedad de consumo, aunque habrán de transcurrir varias décadas para que se produzca el fenómeno inverso y la publicidad se introduzca en el arte como parte esencial de la cultura postmoderna. No será hasta el nacimiento del Pop Art cuando las imágenes de productos y logotipos se conviertan en una fuente temática recurrente para el arte (Díaz, 2010), aunque "dependiendo del carácter de la obra, el contenido iconográfico ha oscilado entre la crítica cultural, la ironía o el homenaje" (Reguera, 2014). Sea como fuere, de lo que no queda duda es que la frontera entre el arte y la publicidad se ha ido diluyendo a lo largo del siglo XX. Tanto es así, que al día de hoy ambos participan en la co-creación del universo iconográfico del consumidor actual, en el que confluyen lo que otrora constituía la alta cultura y la cultura popular (Brea, 2009). Un fenómeno que revela la disolución de lo artístico en la sociedad de la información para dar lugar a la "cultura visual" (Almela, 2004: 1), de modo que la iconosfera ${ }^{3}$, entendida como el conjunto de las imágenes difundidas por la 
cultura visual de masas, “no solo está constituido por las de los objetos físicos portadores de una configuración icónica, sino que incluye las imágenes que los reproducen y difunden a través de los mass media" (Brihuega, 2006: 399).

Es más, se puede afirmar que hoy en día los publicitarios recurren al mundo del arte como referencia constante al igual que lo hicieron en el pasado, cuando era práctica habitual en la industria de la publicidad el contratar a artistas reconocidos para la elaboración de las piezas (Walzer, 2010). En la misma línea, se ha de señalar la existencia de "una tendencia en algunos movimientos artísticos a utilizar recursos procedentes del lenguaje publicitario" (Pérez, 1998: 184), evidenciándose así que las influencias entre el arte y publicidad se han producido en los dos sentidos 4 .

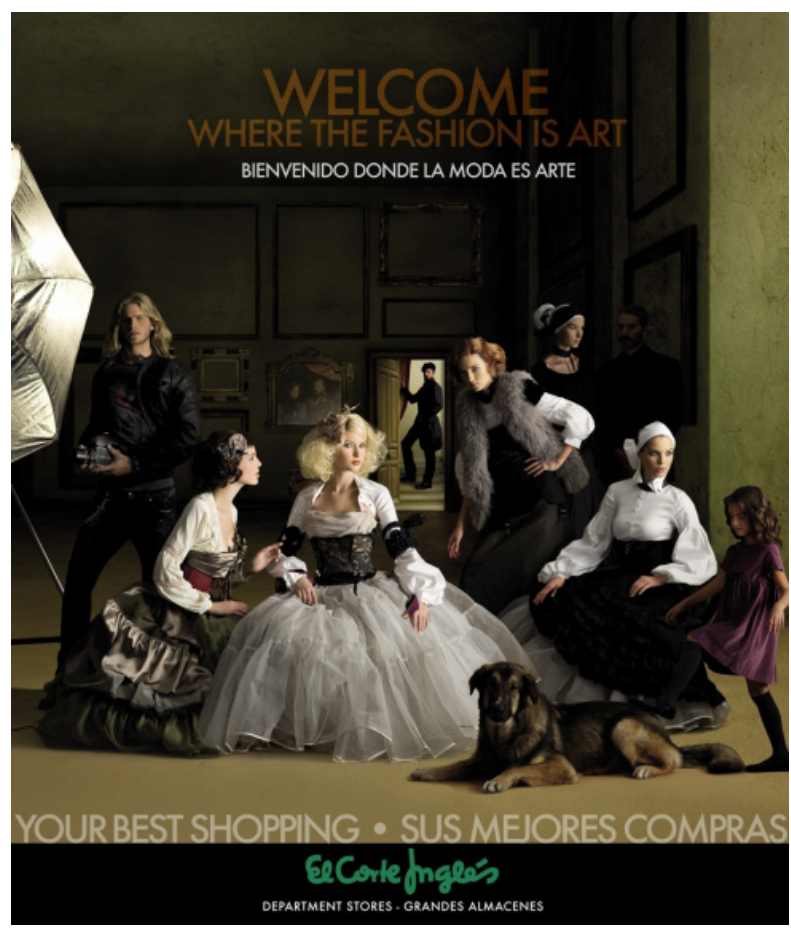

Imagen 1. Reinterpretación libre de Las Meninas o La familia de Felipe IV (Velázquez, 1656) en una campaña publicitaria de El Corte Inglés en 2011 orientada al turista internacional. En este caso el universo simbólico cultural del Museo del Prado fue el insight para atraer al turismo de compras de calidad a la capital madrileña. Fuente: http://24.media.tumblr.com/ tumblr_lb0m5nadrv1qduvm401_500.jpg

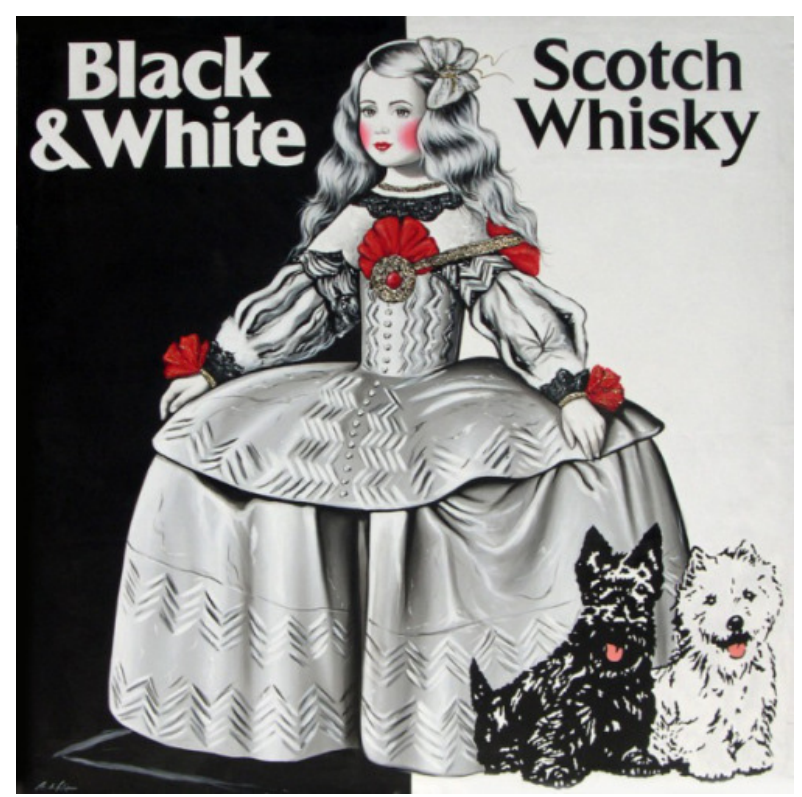

Imagen 2. Menina Black\&White Scotch Whisky (Antonio de Felipe, 1988-1991). Se trata de una reinterpretación libre de la figura de la infanta Margarita que aparece en el centro de Las Meninas de Velázquez (1656) utilizando la identidad visual e iconografía propia de la marca de whisky escocés Black \& White. El artista retrata a la infanta en blanco y negro acompañada por los dos perros, uno blanco y otro negro, emblemas de la marca, recurriendo así a la influencia del lenguaje publicitario en la creación de una pieza artística. Fuente: https://es.pinterest.com/ pin/555490935263195596/?from_navigate=true

A este respecto, son mayoría los autores que promueven una visión integradora a modo de confluencia entre el arte y la publicidad (González, 1997: 81; Alberdi, 2002: 90; Hetsroni \& Tukachinsky, 2005: 94). Defienden la democratización de la cultura, entendida como la puesta a disposición de todos los individuos de los bienes culturales, posibilitando así una comunicación mutua entre el arte y la cultura popular (Eco, 2009: 27-28). Justifican de esta forma la confluencia entre "el gran arte" y la "cultura popular" como consecuencia de la ampliación del campo del objeto artístico (Cruz, 2001: 167). Un fenómeno que plantean como el origen de una renovación del lenguaje visual cotidiano que, por supuesto, evidencia la publicidad (Gúzner \& Fernández, 1991: 62).

Por el contrario, hay autores que apuestan por una visión crítica, calificando de sacrilegio la existencia de una dimensión artística en la publicidad. Los defensores de este punto de vista definen la publicidad como parte integrante de una cultura popular (González, 1997: 81) que en la época moderna alude al entretenimiento, la recreación y los placeres que pueden comprarse como parte de la sociedad de consumo (Spielvogel, 
2010: 968), de forma que la publicidad no sería cultura, sino más bien una anticultura ${ }^{5}$. Un enfoque en el que se integran autores como Asenjo (1999) que, aunque acepta la contribución de la publicidad al conocimiento y reconocimiento del arte, advierte del efecto engañoso de "estetización del mundo" que produce, puesto que las obras de arte incluidas en la publicidad pierden su valor simbólico inicial y se convierten en meras formas sujetas a las modas del consumo de masas.

Entre ambas posturas se sitúan los autores que argumentan que no se trataría de considerar la publicidad como un arte, sino de aceptar que, si bien el arte no es publicidad, en tanto que su función es estética y, la publicidad no es arte, en cuanto que su función es comercial, lo cierto es que ambos lenguajes se retroalimentan (Díaz, 2010: 85). Dadas las influencias mutuas, no debe sorprender la existencia de enfoques aún más audaces que plantean que la transformación del producto en una marca, lo dota de una cualidad intangible que, en cierta medida, lo convierte en icono artístico (Caro, 2012: 148), al tiempo que la obra de arte se convierte a su vez en objeto de consumo en el mercado del arte. De esta forma, la publicidad se desprende de cualquier connotación negativa derivada de su orientación comercial (González, 2007). Tanto es así, que autores como González-Solas (1999) sostienen que arte y publicidad no serían equiparables, sino sustituibles, puesto que lo deseable sería que los anunciantes encargasen arte en lugar de publicidad.

En la misma línea, aunque un paso más allá en la creación de valor percibido a través de las referencias al arte en la comunicación de las marcas, se situaría el denominado branding art, un género especializado dentro del marketing estratégico de la empresa, que promueve el enfoque artístico de la gestión de la marca entendido como "el modo en que las marcas utilizan elementos propios del sistema del arte" (Reguera, 2012). Un punto de vista con el que coinciden Ind y Saracco (2009) al plantear que la expresión de la marca debe ser permeable a nuevas propuestas para ser capaz de adaptarse a nuevos escenarios. En este sentido, el concepto de branding art designaría las asociaciones con determinadas obras/artistas que generarían una transferencia directa de sus estéticas y universos personales hacia la cultura, imagen y visión estratégica de la marca (Reguera, 2014).
Sea como fuere, el interés por el análisis de la relación entre arte y publicidad da buena cuenta la multitud de iniciativas que existen con dicha temática, desde la creación de museos físicos o virtuales, como el Musée de la Publicité de París o el Museo Virtual de Arte Publicitario promovido por el Instituto Cervantes, hasta las iniciativas del sector publicitario para promover el reconocimiento de los valores artísticos de la publicidad, como el Certamen Artístico de Creatividad Publicidad: La publicidad en el Museo, creado en 2006 por la Internacional Adversiting Association (IAA) en colaboración con el Museo Nacional Centro de Arte de Reina Sofía y la Asociación de Productoras Publicitarias Españolas (APPE) y que tuvo su origen en una propuesta similar en el MOMA de Nueva York en 1995 (Hermoso, 2007: 6).

Sin olvidar, por supuesto, la multitud de exposiciones que se han dedicado a la evolución de la vinculación entre el arte y la publicidad, entre otras: Art et Pub dans le monde (Museo de Artes Decorativas, París, 1955), El arte del viaje (Madrid, 1991), Art \& Pub (Centre Georges Pompidou, Paris, 1991), High \& Low: Modern Art and Popular Culture (MOMA, Nueva York, 1990-1991), Signos del siglo. 100 años de diseño gráfico en España (Museo Nacional Centro de Arte Reina Sofía, Madrid, 2000), Maestros del Arte en el Cartel (Museo Valenciano de Ilustración y de Modernidad, Valencia, 2005), Arte y Publicidad. El cartel publicitario: 1890-1960 (Casa Revilla, Valladolid, 2010), 1900. El origen del arte publicitario (Sede Fundación Bancaja, Valencia, 2012) o Graffiti Pop (Casa de Vacas, Madrid, 2015).

En el ámbito de las publicaciones, ya sean de carácter divulgativo o científico, también abundan las dedicadas a dicha cuestión en forma de artículos, libros, capítulos de libro o tesis doctorales. En concreto, cabe señalar el interés de la comunidad universitaria española por investigar las influencias entre el arte y la publicidad, que se concreta en una producción continuada y creciente de tesis doctorales, desde que en 1998 Pérez Gaulí defendiese en la Universidad Complutense de Madrid su investigación sobre la representación de la figura humana en el arte y la publicidad, aunque "este tipo de producción científica se ha centrado más en analizar los trasvases del arte al campo publicitario, que de la publicidad al arte" (De Vicente, 2011: 218). 


\subsection{El uso del arte visual en la comunicación comercial}

Cualquier planteamiento que reflexione sobre la utilización del arte como recurso publicitario debe partir de una definición entre ambos términos. En este sentido, se adoptará de aquí en adelante una perspectiva centrada en el consumidor, entendiendo por arte aquello que los espectadores categorizan como tal, puesto que estudios previos han sugerido que los consumidores poseen un esquema general para el arte (Joy \& Sherry, 2003). En relación al concepto de publicidad, se utilizará una definición desde la perspectiva del marketing, que la considera:

Una transmisión de información impersonal y remunerada, efectuada a través de un medio de comunicación, dirigida hacia un público objetivo, en la que se identifica el emisor ${ }^{6}$ y que tiene un objetivo específico: de forma inmediata o no, trata de estimular la demanda de un producto o de cambiar la opinión o comportamiento del consumidor" (Santesmanes, Merino, Sánchez y Pintado, 2009: 238).

Existe una necesidad de profundizar en el conocimiento de la relación entre arte y publicidad, en este caso, desde el punto de vista de la gestión de la marca. A este respecto, se pueden resumir en tres las causas fundamentales por las que la publicidad recurre al arte: para inspirarse, para simplificar la comprensión del mensaje y/o para diferenciarse dando valor añadido al producto (Cavalli, 2007). No hay duda que los publicitarios necesitan encontrar imágenes en las que inspirarse para crear sus anuncios $y$, en este sentido, las transferencias del arte a la vida cotidiana a través de la publicidad son una constante (Asenjo, 1998: 53). Por otro lado, al inspirarse en los esquemas de percepción, temas o simbología reconocida universalmente, la publicidad se vuelve más fácilmente interpretable por el público $y$, en consecuencia, ve reforzada la eficacia de sus mensajes (Sarmiento, 2011: 138).

Un enfoque diferente es el planteado por la sociología del arte, que concibe la obra de arte como transmisora de valores sociales, de forma que el arte es útil a la publicidad porque denota riqueza y espiritualidad, e implica que la compra propuesta es un lujo y un valor cultural ${ }^{9}$. Se trata de incorporar un valor añadido al producto haciéndolo parecer próximo a aquello que ya tiene un valor establecido, en este caso el arte, puesto que la proximidad es percibida como similitud (Alberdi, 2002: 90). Es por ello que la publicidad acude al arte para que le contagie su dignidad al producto (Fernández, 1991: 201).

De hecho, diversos estudios en el ámbito de la psicología social han develado que el arte visual influye positivamente en la percepción y evaluación de los productos o marcas que lo incluyen en su comunicación. Se trata de un efecto de contagio entendido como un mecanismo según el cual, el contacto directo o indirecto entre dos objetos puede dar lugar a una transferencia permanente de las propiedades de un objeto (el arte) al otro (el producto anunciado), y que Hagtvedt y Patrick (2008) denominaron efecto de transfusión del arte. En sus investigaciones comprobaron que el arte connota excelencia, lujo y refinamiento y, que estas connotaciones, se comunican a los productos que utilizan el arte en su publicidad, con independencia tanto del contenido de la obra de arte, como del tipo de producto. Se trataría así de un efecto generalizable y unido siempre a una percepción favorable, al asociarse el arte con la alta cultura, el prestigio y el elitismo (Hoffman, 2002: 6).

Esto es precisamente lo que distingue al arte visual de otros fenómenos sensoriales, como el olor (Spangenberg, Crowley \& Henderson, 1996), la música (Alpert \& Alpert, 1990) o incluso de otros estímulos visuales como imágenes no-arte. Unos y otros estudios se han visto ampliados recientemente por las investigaciones sobre la influencia de emociones discretas en el comportamiento del consumidor, incluida la emoción de disgusto (Nowlis, Mandel \& McCabe, 2004), que se ha demostrado implicada en un efecto de transfusión similar al del arte, aunque de connotaciones negativas.

Por último, conviene al menos mencionar otras de las razones posibles para la inclusión del arte en la comunicación comercial citadas en la literatura especializada. Se alude a su uso para justificar el sobreprecio de ciertos productos (Eguizábal, 1999: 33-34), para incrementar la notoriedad del producto 0 la marca (Almela, 2004) o para trasladar el sentido de la pieza artística a la actividad del producto anunciado (Jiménez, 2008: 160). Conviene no obviar que, en ocasiones, es el arte el que recurre a la publicidad, ya sea como método de crítica cultural o como pauta de acercamiento a la sociedad contemporánea (Reguera, 2014), sin renunciar a su utilidad como medio de divulgación de los estilos artísticos poniendo el talento de reconocidos artistas al servicio de los anunciantes. 


\section{Metodología}

En este artículo se presenta una propuesta de categorización de las estrategias comerciales apoyadas en el arte visual actualmente utilizadas en la comunicación comercial, que se materializa en once tipologías. Tras una primera fase exploratoria en la que se procedió a la revisión bibliográfica de las referencias académicas más actuales sobre la relación entre el arte y la publicidad, se llevó a cabo la recolección de las piezas publicitarias con alusiones al arte visual para su posterior clasificación. La recopilación se realizó entre el 1 y el 27 de julio de 2016 a través de Coloribus ${ }^{8}$, un repositorio on line con más de dos millones de anuncios de todo el mundo.

Con el fin de obtener una muestra lo más amplia y representativa posible, se optó por realizar búsquedas genéricas, prescindiendo en todas las consultas de cualquier restricción por el país de procedencia o la fecha de creación/publicación de las piezas. Tras la introducción en el buscador de Coloribus de los descriptores "arte", "arte visual", "pintura" y "museo", se consultó el nombre de cada uno de los 142 maestros de la pintura que figuran en la lista de autores sugeridos por la pinacoteca virtual Ciudad de la Pintura'. Dado que la cultura visual tiene un carácter provisional y se adapta a cada época, ha sido la selección de artistas de este archivo digital, uno de los más utilizados en el ámbito académico español, el criterio elegido para detectar las piezas publicitarias con referencias a las obras más reconocidas de la historia de la pintura presentes en el imaginario colectivo.

Del total de resultados obtenidos, se consideraron como parte de la muestra objeto de estudio solamente las piezas pertenecientes a las categorías de publicidad en televisión, publicidad impresa, publicidad al aire libre y diseño de producto y logotipos ${ }^{10}$. Pese a que la influencia del arte en la publicidad no se limita solo a las piezas gráficas o audiovisuales, sino que podemos encontrarla también en las técnicas de la publicidad no convencional ${ }^{11}$, ya sea en forma de street marketing (Llorente \& García, 2016), ambient marketing (Torreblanca \& Lorente, 2012: 6) o de "performance" publicitarias tipo flashmob (RodríguezPina, 2016), entre otras muchas posibilidades, intencionalmente se ha acotado el análisis al arte visual. El motivo reside en que la presencia de arte no visual como recurso publicitario, al margen de la música, es muy minoritaria y, en el caso de ésta, se utiliza supeditada a la imagen (Vilasuso, 2013).
Para la definición de los criterios de clasificación de las piezas publicitarias se ha recurrido a la trasposición desde el campo de la lingüística de la propuesta de Hjemslev ${ }^{12}$ para el estudio del significante en base a la dicotomía expresión/contenido (Cifuentes, 2006: 6), que se corresponde con el binomio significante/ significado de la escuela saussureana (Romero, 2014). Según Hjelmslev la lengua y, por analogía, el lenguaje publicitario, es una red de funciones semióticas en cada una de las cuales se ponen en relación dos argumentos -la forma de la expresión y la forma del contenido-, lo que aplicado al objeto de análisis permite definir los criterios de clasificación de primer orden. De su aplicación, resultan dos categorías primarias:

a) según la forma de expresión de la inserción del arte en la publicidad, que se aplicará a los dos elementos característicos de las piezas publicitarias convencionales -el texto y la imagen- $y$,

b) en función de la forma del contenido, que se circunscribe al tipo de relación, desde el punto de vista de la gestión de la marca, que se establece entre la referencia al arte y el producto/marca que lo emplea en su comunicación.

A continuación se presentan las variantes del sistema de clasificación, acompañadas de algunas piezas publicitarias, a modo de ejemplo, que han sido seleccionadas por representar fielmente las características definitorias de cada subcategoría, con independencia de la fecha o país de difusión. Se ha de señalar, no obstante, que la casuística es tan abundante y diversa, que se vuelve inabarcable en su totalidad, de ahí que ésta sea solo una propuesta tipológica inicial a modo de guía que, en el futuro, deberá ampliarse. Así mismo, se ha de tener en cuenta que las categorías no son excluyentes; de hecho, con frecuencia son complementarias, de forma que el criterio de clasificación se ajustaría al tipo de uso publicitario del arte dominante de entre todos los presentes en cada caso. 


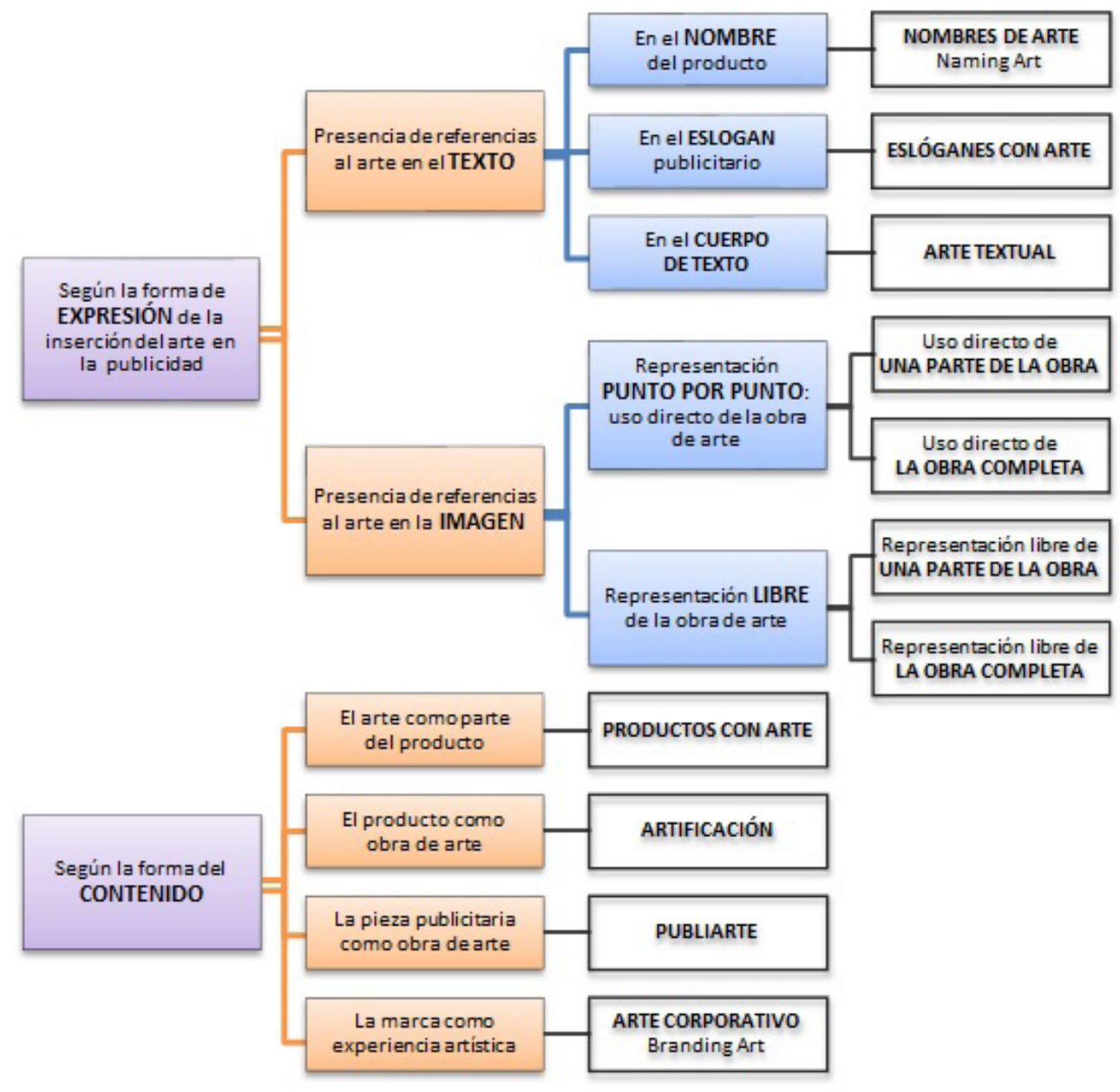

Imagen 3. Propuesta de clasificación del uso del arte visual en la comunicación comercial. Fuente: elaboración propia.

\section{Tipologías del uso del arte visual en la comunicación comercial}

\subsection{Tipos de publicidad con arte según la forma de expresión}

Desde los primeros análisis del mensaje publicitario, existen dudas acerca de si es el texto el que se subordina a la imagen o a la inversa (Hernando, 1994). Lo cierto es que las piezas publicitarias en las que la presencia del código lingüístico escasea son excepcionales y, en la mayoría de ocasiones, se reservan para los productos de lujo, en un intento por destacar su exclusividad (Díaz-Soloaga, 2007), siendo lo más habitual que ambos códigos coexistan (Boscán \& Mendoza, 2004). No obstante, Roland Barthes (1977) se planteaba hace ya casi medio siglo si se podría suprimir el texto de las piezas publicitarias por redundante, dado que, en su opinión, es la imagen la que desempeñaría la función persuasiva.

\subsubsection{Presencia de referencias al arte en el texto publicitario}

Sirvan como ejemplo de la capacidad del texto publicitario para crear una comunicación diferencial, las estrategias que incluyen en él referencias al arte, ya sea como técnica de naming -incorporando el nombre de un artista en el del producto, para vincular su prestigio y universo iconográfico a la marca-, o bien, insertando el término "arte" en el eslogan, para incrementar el valor percibido. Sin olvidar, por supuesto, las referencias al arte en el texto publicitario, que mayoritariamente adoptan la forma de frases célebres de artistas reconocidos.

Entre los casos naming con referencias al arte, destacan el Renault Clio graffiti, en el mercado entre 1991 y 1998, o el Citroën Xsara Picasso, lanzado en 1999, aunque el "apellidarse" Picasso no impidió que la competencia recurriese al mismo artista para implementar una estrategia de mecenazgo cultural comunicada mediante otra campaña con referencias al arte. Es lo que hizo Mazda en 2006 con motivo del patrocinio de la exposición de Picasso en la Galería Nacional de Victoria en Melbourne. 


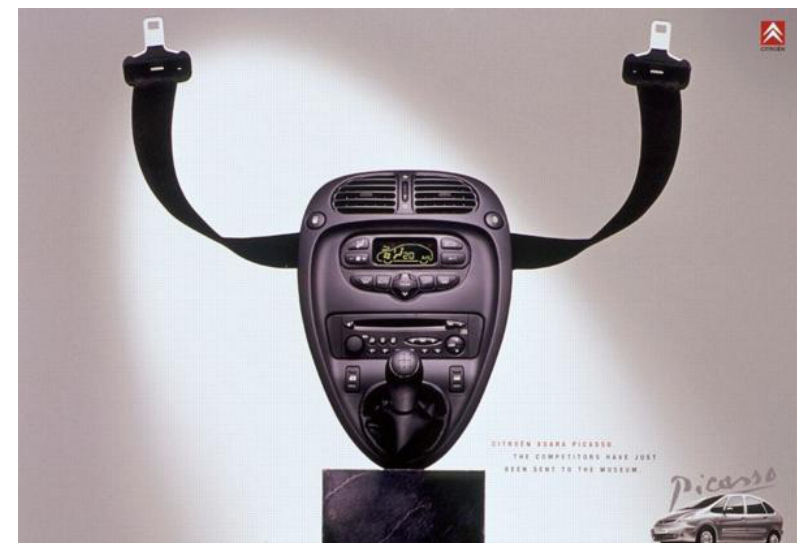

Imagen 4. Campaña del Citroën Xsara Picasso creada por DPZ Sao Paulo en 2002 con la imagen de un toro español construida a partir de elementos del coche que sitúan en una peana como si de una escultura se tratara. Fuente: https://www.coloribus.com/ adsarchive/prints/citroen-xsara-picasso-bull-4457005/

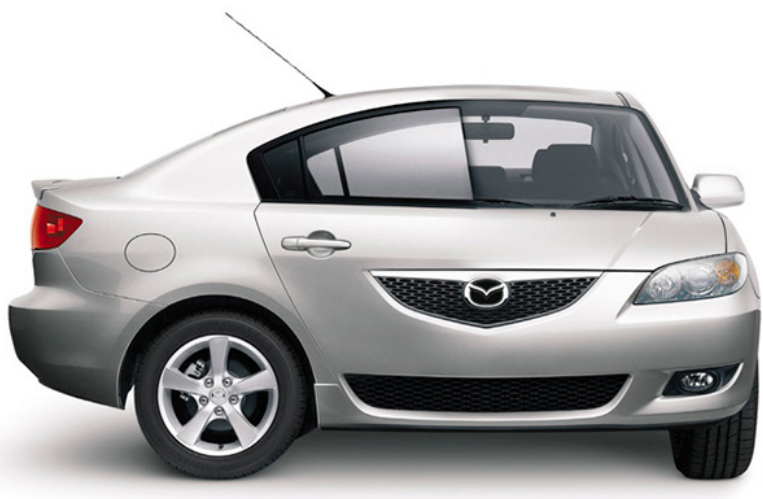

Imagen 5. Campaña de la agencia CHE para Mazda, con motivo del patrocinio de la exposición de Picasso en la Galería Nacional de Victoria en Melbourne en 2006. Fuente: http://bunkerpop. $\mathrm{mx} / \mathrm{wp}$-content/uploads/2014/04/10_080414_1396971570_95.jpg

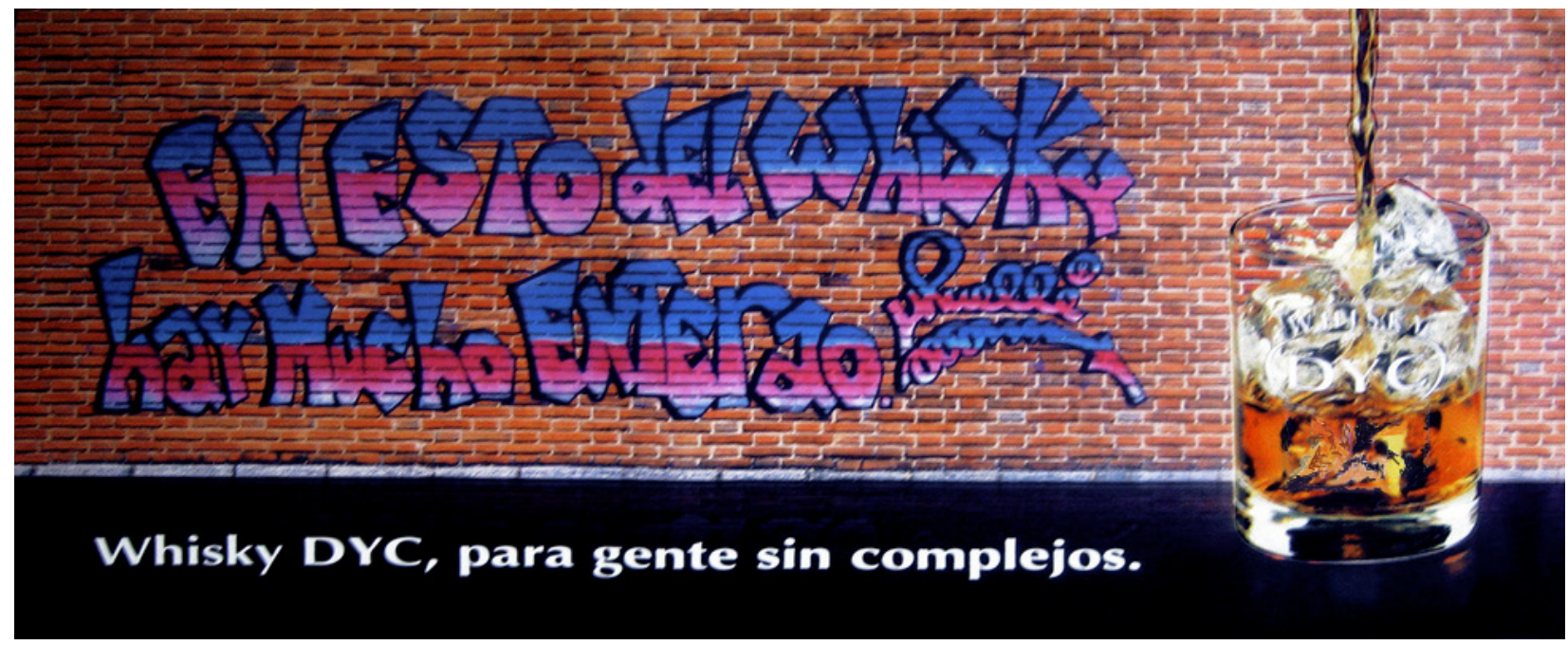

Lo mismo ha sucedido con las marcas que han apostado por eslóganes con arte, incorporando en ellos el término arte, entre otras: Air France que se anunciaba como "El Arte de volar", Mont Blanc como "El Arte de escribir", Nokia como “El Arte de comunicar", Tiffany's como "El Arte de comprar", Louis Vuitton como "El Arte de viajar" o, más recientemente, "El arte de regalar" de Ferrero Golden Gallery ${ }^{13}$. Un mensaje que por reiterativo y compartido deja de ser diferenciador.

Por el contrario, sí suele serlo la inclusión en el texto de las piezas publicitarias de referencias al arte (arte textual). En la mayoría de los casos se trata de frases de artistas reconocidos, como en la campaña de Whisky DYC de1993, “Para gente sin complejos", en la que Muelle ${ }^{14}$, máximo exponente del arte urbano español por aquel entonces, firmaba el texto.
Imagen 6. Texto del artista urbano Muelle utilizado como recurso publicitario. Fuente: https://artedemadrid.files.wordpress com/2009/02/muelle-anuncio.jpg

\subsubsection{Presencia de referencias al arte en la imagen del anuncio}

Esta es, sin duda ninguna, la categoría más numerosa entre las tipologías de la utilización publicitaria del arte. Bien sea como uso directo de la obra de arte, o bien, en una reinterpretación como representación libre de la misma, con más o menos verosimilitud, los ejemplos abundan. Tanto los referidos al uso de una parte de la obra, como a obras completas. 
Probablemente sea porque es la forma más eficaz de generar el efecto de transfusión del arte, dado que cuanto mayor se explicite su presencia, y mayor verosimilitud exista con la obra real, mayor es la probabilidad de que las connotaciones positivas asociadas al arte se transfieran al producto. Es por ello que la mejor de las situaciones posibles deriva del uso directo de una obra de arte completa, de la que es ejemplo paradigmático la inclusión en la comunicación publicitaria de La Lechera, la obra homónima que Veermer pintó en 1658.

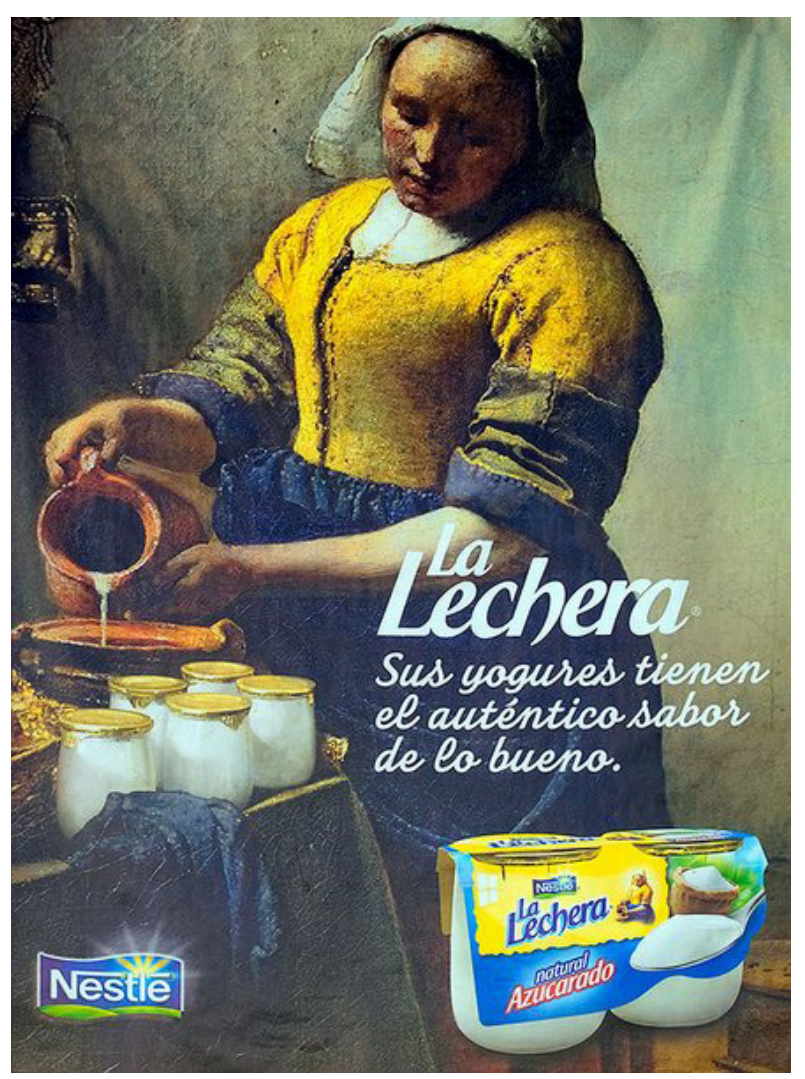

Imagen 7. Campaña gráfica de La Lechera basada en la obra homónima de Vermeer. Fuente: http://www.vamosapublicidad. com/wp-content/uploads/2010/02/cartel-la-lechera-pq.jpg

En otras ocasiones, se limita la representación punto por punto a una parte de la obra, como en el caso del logotipo de La Caixa, hoy Caixabank, creado en 1980 por Joan Miró por encargo de la entidad bancaria a través de la prestigiosa consultora americana Landor, que facilitó al artista un asterisco con dos puntos para que lo reinterpretara e incluyera como un elemento más en la elaboración de un tapiz junto con el artista Josep Royo. Pero ambos transformaron en la estrella de cinco puntas que hoy día representa el carácter innovador y mediterráneo del banco. En su momento, el nuevo logotipo supuso una ruptura con la imagen que hasta entonces ofrecían las entidades bancarias, dotándola de un contenido emocional.

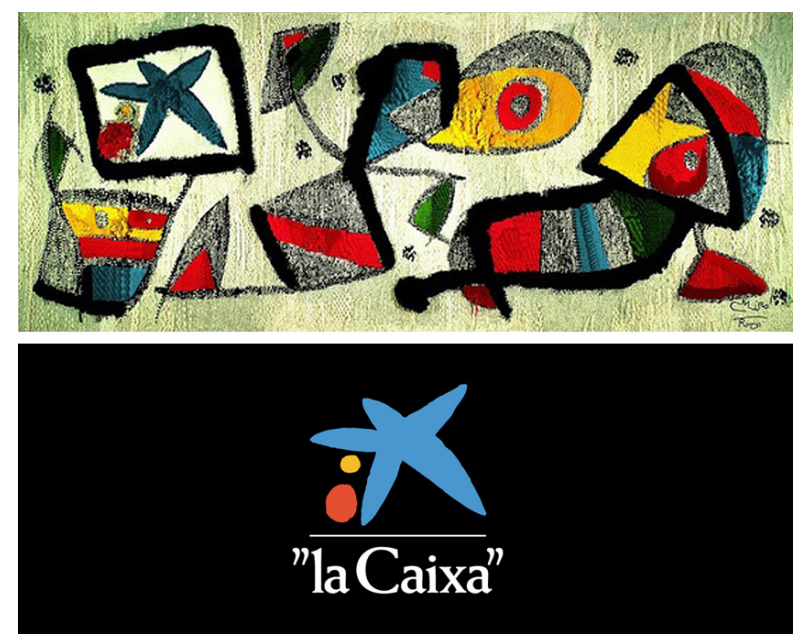

Imagen 8. Tapiz de Joan Miró y Josep Royo cuyo detalle de la estrella utilizado como logotipo de La Caixa, hoy Caixabank, marcó tendencia en la década de los 80, cuando surgieron multitud de logotipos del mismo estilo "mironiano". Fuente: http://www. onaccent.com/wp-content/uploads/2014/04/miro-la-caixa.jpg

Conforme el uso directo de la obra de arte es sustituida por una representación libre de la misma, ya sea de una parte de la obra o de la obra completa, más complejo es para el público identificarla y, en consecuencia, percibir el valor añadido al producto con la inclusión de la referencia artística. 


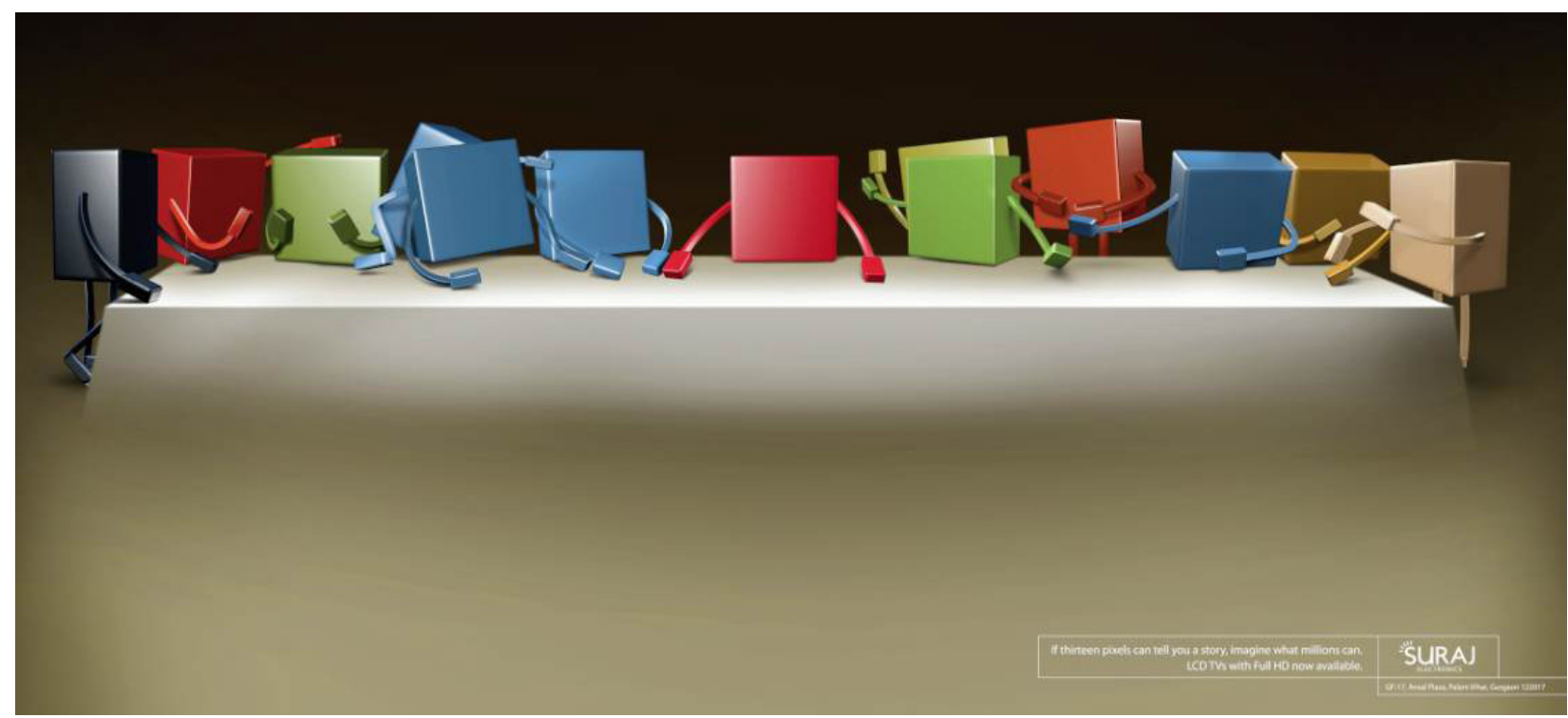

Imagen 9. La representación más o menos libre del Autorretrato (1889) de Van Gogh ha sido una de las más empleadas por las marcas. De izquierda a derecha y de arriba hacia abajo: propuesta de campaña gráfica para Lego (M. Sodano, Milán, 2012), campaña gráfica de Skenpoint (Newmoment, Macedonia, 2009), campaña gráfica de Nescafé (Prodigius, Noruega, 2014), campaña de Alliance Française (Garwich BBDO, Quito, 2007) y campaña de KelOptic (Y\&R, París, 2012). Fuente: http://www.coloribus.com/
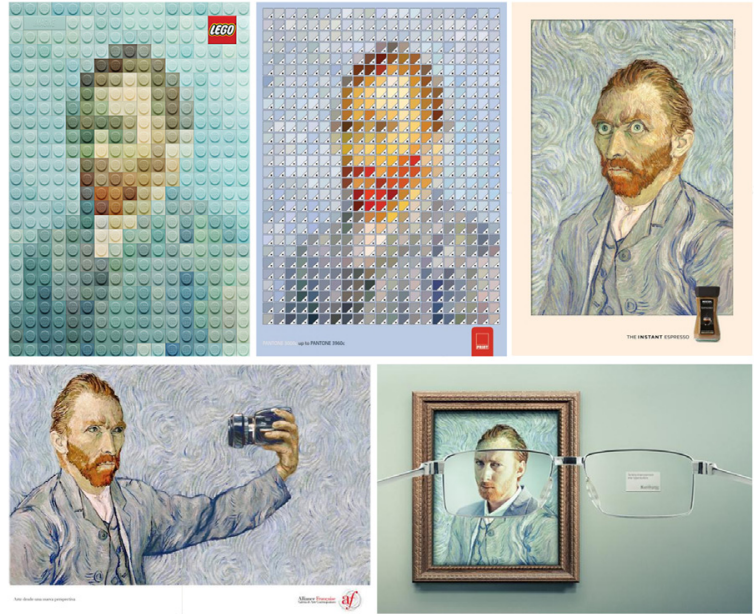

Imagen 10. Bajo el eslogan "Si trece píxeles pueden contar una historia, imagínate lo que harán millones" la empresa Suraj Electronics encargó en 2009 a la agencia JWT (Nueva Delhi, India) esta campaña publicitaria a modo de reinterpretación libre del cuadro La última cena (Leonardo da Vinci, 14951497). Fuente: http://catalogo.artium.org/sites/default/files/ imagenesbody/10/2014/x_pixel.jpg

Y es que en la cultura visual de masas de la sociedad actual, en la que los lenguajes artístico y publicitario se entremezclan, situando a los artistas y publicitarios en un territorio común, las referencias a obras de arte emblemáticas son un recurso habitual. Es por ello que cuanto menor sea tanto la fidelidad a la obra de arte original como la parte de la obra incluida en la publicidad, mayor debe ser el peso de la obra en la cultura visual de la sociedad contemporánea, para posibilitar así que el reconocimiento de la pieza por el público sea inmediato $y$, en consecuencia, que el efecto de transfusión del arte tenga lugar.

\subsection{Tipos de publicidad con arte según la forma del contenido}

En el sistema de clasificación propuesto, los usos del arte como recursos de la comunicación comercial aparecen organizados en cuatro tipologías según la relación que se establece entre el arte y el producto/ marca que lo emplea en su comunicación, realizándose el análisis desde el punto de vista de la gestión de la marca.

\subsubsection{Productos con arte}

En numerosos casos, se observa cómo el arte se convierte en parte de un producto -son productos con arte-, pero sin ir más allá. Se trata de un mero proceso de adición, en el que se busca generar un efecto de transfusión, casi siempre a través de la inclusión de obras de arte en el packaging de los productos, pero sin hacer referencia aún a la consideración artística del producto. Se ha de distinguir entre un primer paso, que sería la estampación de una obra reconocida en el packaging del producto y, el dar un paso más en el uso publicitario del valor artístico, encargando a un artista una obra de nueva creación para el producto. Siendo ortodoxos, en la mayoría de los casos en los que esto sucede no se trata de publicidad en sentido estricto, pero sí de comunicación comercial, puesto 
que actualmente se considera el packaging como una forma de publicidad silenciosa que "tiene como objetivo primario atraer la atención de los clientes y ser la principal ventana de comunicación hacia el consumidor" (Rodríguez, 2014). Desde la perspectiva de la gestión de marca, se podría circunscribir a una estrategia de creación de imagen de marca previa a la comunicación publicitaria propiamente dicha.

Un ejemplo de esto lo encontramos en el proyecto EnsaimadArt, que busca dotar al tradicional embalaje de las ensaimadas mallorquinas de un nuevo contenido visual. Se trata de reformular la imagen del producto para dotarla de contemporaneidad a través de la inclusión de obras de artistas y diseñadores contemporáneos en el packaging. No obstante, se mantiene el envase octogonal característico para crear una asociación con la imagen tradicional que el consumidor tiene del producto.

Imagen 11. Packaging tradicional de ensaimada mallorquina (izquierda) junto a una propuesta de packaging de EnsaimadArt con un diseño de Javier Mariscal, conocido internacionalmente por ser el diseñador de Cobi, la mascota de los Juegos Olímpicos de Barcelona 1992. Fuente: http://www.alacartaparados.es/ wp-content/uploads/2012/10/javier_mariscal.jpg
Es la misma estrategia que viene utilizando desde 1945 Mouton Rothschild, cuando comenzó a encargar a artistas famosos el diseño de la etiqueta de cada añada. Jean Cocteau (1947), George Braque (1955), Salvador Dalí (1958), Joan Miró (1969), Marc Chagall (1970), Kandinsky (1971), Pablo Picasso (1973), Andy Warhol (1975), Francis Bacon (1990), Antoni Tàpies (1995) o Miquel Barceló (2012) son solo algunos de los artistas que han contribuido a crear un auténtico museo en botellas de vino ${ }^{15}$.

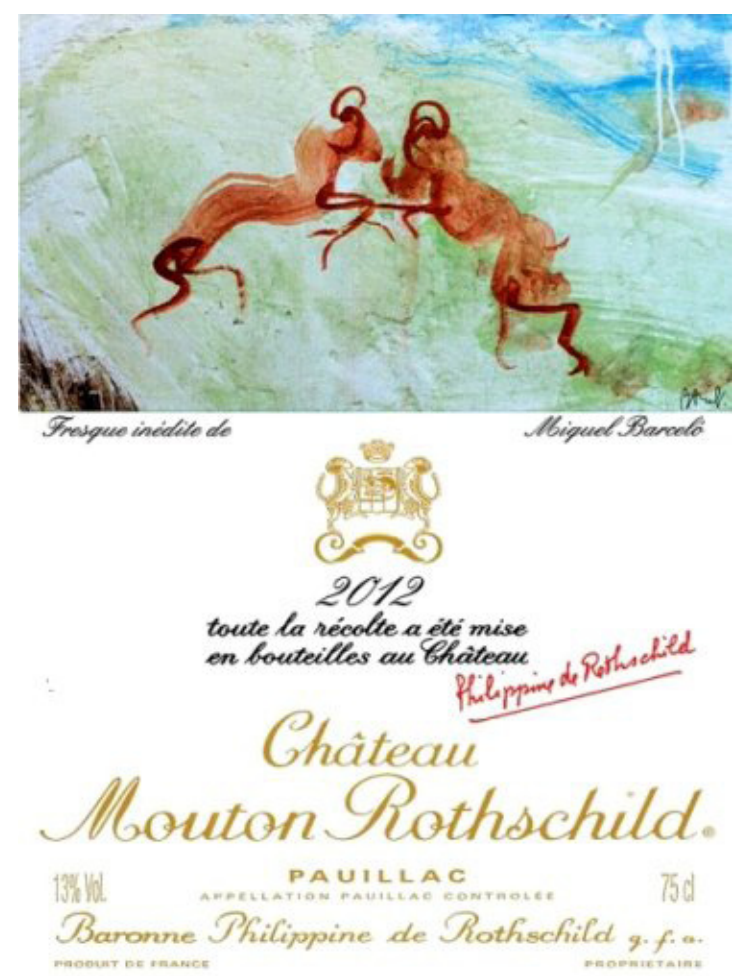

Imagen 12. Etiqueta de Mouton Rothschild diseñada por Miquel Barceló para la cosecha de 2012. Fuente: http://www.theartistlabels. com/mouton/labels/2012.jpg
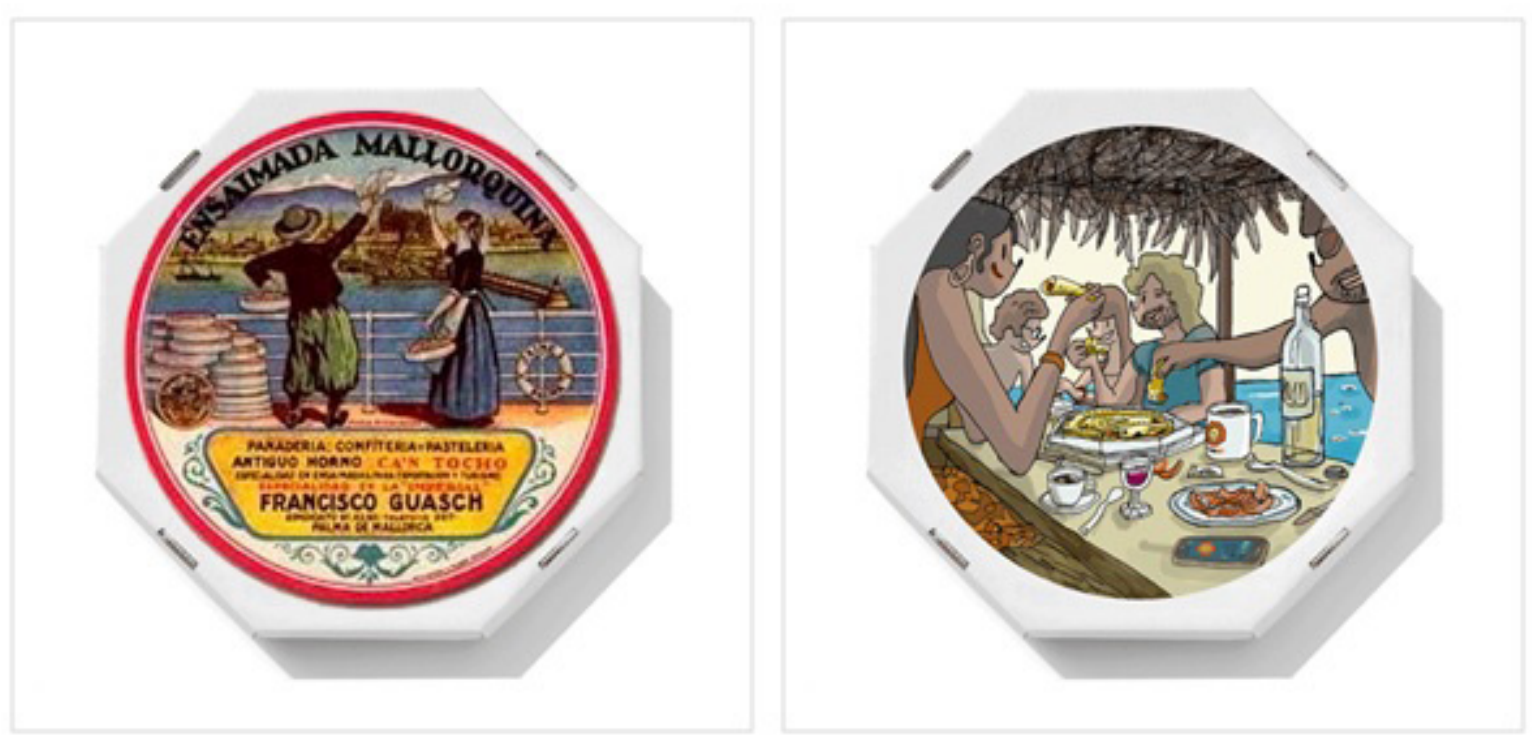


\subsubsection{Artificación}

El siguiente paso en la integración del arte con el producto/marca, que lo usa como recurso publicitario, consiste en las estrategias de artificación que presentan el producto equiparándolo con una obra de arte en sí mismo. Se trata de dotarlo de una identidad artística. En este punto, sí se puede considerar la existencia de una estrategia de gestión de la imagen de marca a través de la comunicación publicitaria. Por ejemplo, la compañía De Beers, ha utilizado el arte en la promoción de su imagen, transmitiendo la idea de que los diamantes, como las pinturas, son obras de arte únicas. En la misma línea, la campaña de Nescafé Dolce Gusto "el arte moderno del café" -de nuevo otro eslogan con arte-, hace énfasis en el diseño innovador de la cafetera, mostrando en el anuncio para televisión cómo varias obras de arte clásicas conversan entre sí, calificando a la cafetera de obra de arte moderna y confundiéndola con la nueva pieza estrella de la colección ${ }^{16}$. Tanto es así, que la marca ha lanzado al mercado varias ediciones limitadas con diseños de la cafetera inspirados en la obra de reconocidos artistas contemporáneos como Roy Lichtenstein o Frida Kahlo, posicionándose para el consumidor como una forma accesible de introducir "arte moderno" en sus hogares.

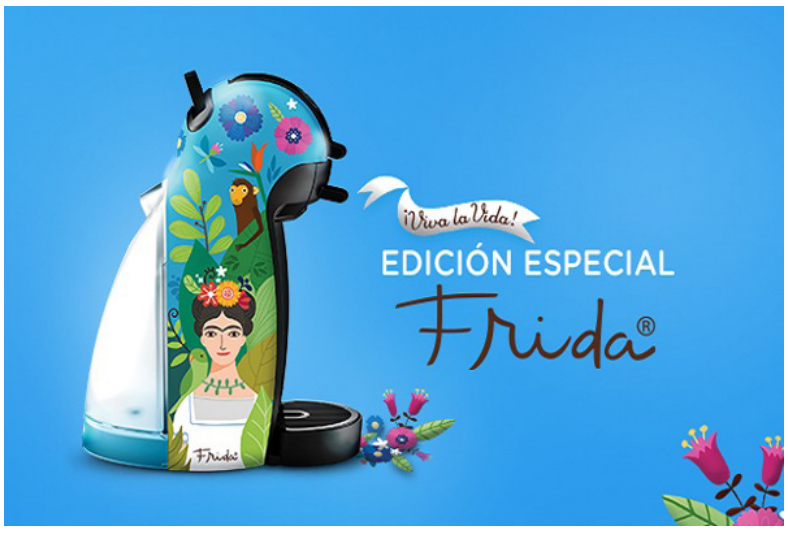

Imagen 13. Modelo Frida Piccolo de Nescafé Dolce Gusto inspirado en la obra de Frida Kahlo. Fuente:http://mamaejecutiva.net/www/ wp-content/uploads/2014/05/319.jpg

\subsubsection{Publiarte}

La tercera variante entre las tipologías en función de la forma del contenido publicitario se corresponde con el publiarte, entendido como un "nuevo género publicitario porque no encontraba otra expresión más afortunada para designar estos nuevos anuncios, que cada vez se parecen menos a los comunicados comerciales y más a las obras de arte" (Gurrea, 1998: 169).

Se trata de arte creado exclusivamente para la promoción de un producto, de forma que el producto deja de ser tratado como una obra de arte en sí mismo y pasa a ser propuesto como objeto de tratamiento artístico. En este caso, la gestión de la marca se amplía y va más allá de la comunicación publicitaria propiamente dicha. Un ejemplo paradigmático es la estrategia empleada por la marca Absolut con su encargo a Andy Warhol, como primero de una serie de artistas reconocidos, en la interpretación en forma de ilustración de su popular botella. En 1986 el artista participó en la creación de diferentes piezas gráficas para la marca, iniciando el movimiento denominado Absolut Art. En consecuencia, es la pieza publicitaria la que se eleva a la categoría de obra artística ${ }^{17}$ y no el producto, lo que diferencia esta tipología de la artificación.

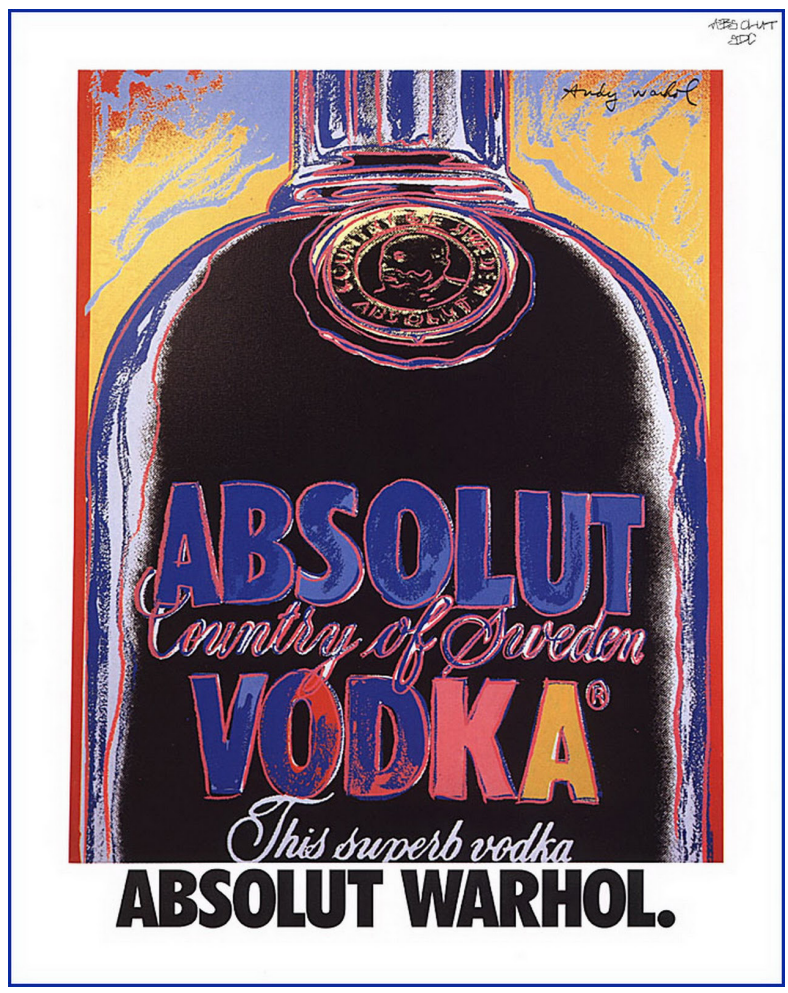

Imagen 14. Ilustración de Andy Warhol para Absolut Vodka (1986) Fuente: http://spritmuseum.se/wp-content/uploads/2015/01/ absolut-warhol-wb.gif 
A esta misma categoría pertenecerían los fashion films, cortos de cine o vídeos digitales de directores reconocidos que protagonizan modelos y actores/ actrices famosos, que las grandes marcas de moda empezaron a usar como estrategia de marketing viral con la intención de generar contenido para la marca (Ramos-Serrano \& Pineda, 2009) y a los que cada vez más recurren marcas de otros sectores, como el de la cosmética o la automoción (Del Pino \& Castelló, 2015). Su calidad artística hace que merezcan la consideración de publiarte.

\subsubsection{Arte corporativo (branding art)}

El último paso sería la implementación de un enfoque artístico de la gestión de la marca mediante el arte corporativo (branding art), del que es ejemplo la propuesta MTNG Experience de la marca de calzado Mustang, que ha transformado la sede principal de sus oficinas en Elche (Alicante), fusionando el espacio de trabajo con una galería de arte -Mustang Art Gallery (MAG)- destinada a la promoción y difusión del arte contemporáneo. En la misma línea, la marca de saneamientos Roca ha creado cinco espacios de experiencia de marca -Roca Barcelona Gallery, Roca Madrid Gallery, Roca Lisboa Gallery, Roca Sanghai Gallery y Roca London Gallery-en los que se exhiben los productos de la marca como piezas de arte. La marca pretende proveer al público de una experiencia visual e interactiva en espacios que a modo de instalaciones expositivas vanguardistas den a conocer todos aquellos elementos relacionados con el mundo del baño. Un concepto innovador en el que el mismo espacio es un showroom, que sirve de escaparate para los productos más emblemáticos de la marca, al tiempo que alberga actividades sociales, culturales y expositivas relacionadas con los valores de la compañía, como la eficiencia energética, el ahorro, la sostenibilidad, el diseño o la innovación. El resultado es que el arte se implementa en la gestión estratégica de la marca, sustituyendo lo que en el management tradicional no sería más que la apertura de un punto de venta, por la creación de un espacio a modo de punto de encuentro social y cultural para los visitantes, cuya actividad enfocada a la promoción del arte y la cultura revierte en la generación de valor de marca.

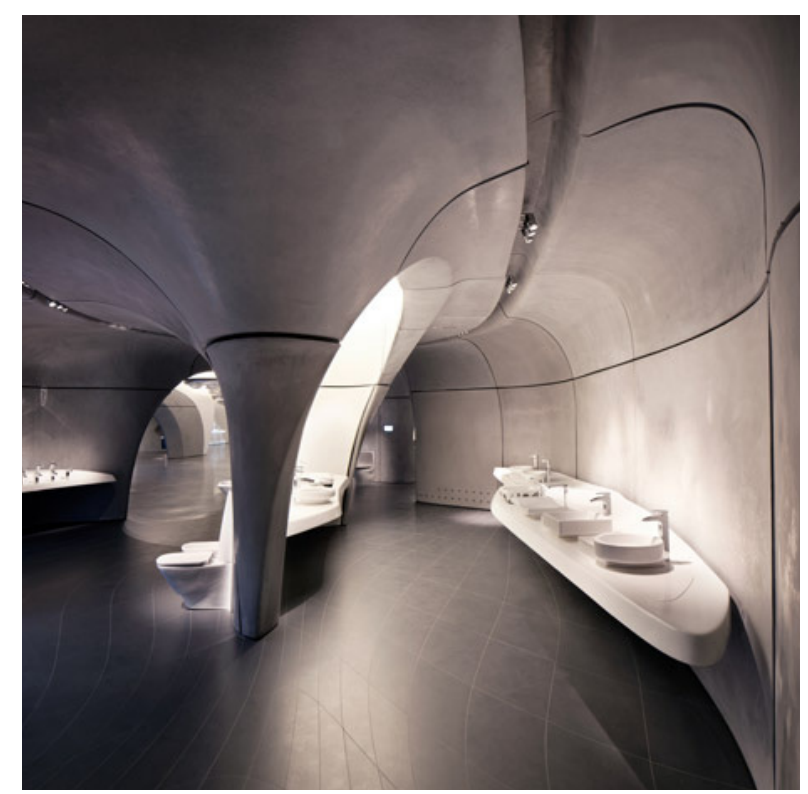

Imagen 15. Interior de la vanguardista Roca London Gallery donde los productos de la marca comparten espacio expositivo con piezas artísticas. Fuente: http://fancycribs.com/wp-content/uploads/2011/10/ Roca-London-Gallery-by-Zaha-Hadid-Architects-9.jpg 


\section{Conclusiones}

La alta competitividad del mercado actual junto con el nuevo tipo de consumidor, más exigente, más informado, más activo, multipantalla y cada vez más escéptico hacia el discurso de la publicidad convencional a la que está sobreexpuesto, obligan a las marcas a buscar su diferenciación mediante estrategias de gestión innovadoras y que incrementen el valor percibido por el consumidor, dada la homogeneidad en las características físicas y funcionales de los productos. En este contexto, se vuelve necesaria una comunicación relevante, útil y emocional, con la que el consumidor pueda implicarse. Es por ello que la inclusión de referencias al arte en la comunicación comercial de las marcas se postula como una fórmula válida para conseguir el vínculo con el consumidor. La relación entre arte y publicidad es larga en el tiempo y cada vez más estrecha, de forma que frente a la visión crítica de los que niegan la dimensión artística de la publicidad, son cada vez más numerosos los defensores de una visión integradora, que aboga por la confluencia del arte y la publicidad en un espacio compartido en el que ambos se retroalimentan.

Demostrada empíricamente la influencia del arte visual en la percepción y evaluación favorable de los productos de consumo en cuya publicidad figura lefecto de transfusión del arte), son cada vez más numerosas las marcas que recurren a esta estrategia. Las diferentes fórmulas que utilizan en la implementación del arte visual como recurso publicitario pueden clasificarse en once tipologías distintas en función de la forma de expresión del arte en el texto y en la imagen, así como de la forma del contenido que adopte, entendido como el tipo de relación, desde el punto de vista de la gestión de la marca, que se establece entre la referencia al arte y el producto/ marca que lo emplea en su comunicación.

La abundante casuística existente, así como la renovación constante de las estrategias publicitarias, plantea desafíos en lo que a la taxonomía del uso del arte en la comunicación comercial se refiere, que hacen de ésta una propuesta de clasificación elemental, pero válida, que abre nuevas vías de investigación a desarrollar en el futuro.

\section{Notas}

1. El modelo propuesto por Shannon y Weaver (1948) intenta determinar la forma más económica, rápida y segura de codificar un mensaje, sin que la presencia de algún ruido complique su transmisión.

2. El término fue acuñado por el sociólogo Alvin Toffler en 1980 en su libro La tercera ola para definir al consumidor del futuro, un sujeto en quien convergen los roles de productor y consumidor de la información.

3. Término acuñado por el teórico Gilbert Cohen-Seat para designar un fenómeno que define, en esencia, como urbano y contemporáneo, pese a que el término cultura de masas al que se vincula goza de la imprecisión de no definir lo que es masa ni lo que es cultura (Eco, 2009: 27-28). No obstante, lo que detectamos en este conjunto de imágenes es una estructura de "existencia cultural" compartimentada en tres niveles - High-Cult, Mild-Cult y Low-Cult para autores como McDonald, Greenberg - Bell-, que coexisten con otros estratos intermedios y entre los que la contaminación es mutua (Brihuega, 2006: 402). "Un escenario intersticial de un espacio crecido en los entremedios, en el inbetween de disciplinas y prácticas" (Brea, 2009: 22).

4. El ejemplo más emblemático en la historia de la publicidad española es el de la etiqueta de Anís del Mono. En 1897, Vicente Bosch organiza el primer concurso de carteles para la marca de anís, al que se presentaron algunos de los mejores pintores de entonces y que ganó Ramón Casas con su cartel Mona y mono. Una incursión del arte en la publicidad que se acabaría transformando en lo contrario, cuando Diego Rivera incluyó la botella de anís en Naturaleza muerta con balalaika (1913). Un año después, Juan Gris utilizó la etiqueta de Anís del Mono como tema principal de su obra, La botella de anís (1914), al igual que haría Pablo Picasso en Botella de Anís del Mono, vaso de anís y naipe (1915).

5. Lo que subyace es la tan manida distinción propia de la cultura occidental entre las zonas intocables de la cultura "arte" y las zonas despreciables de la misma "publicidad". Un planteamiento según el cual el arte sería propio de la alta cultura, un concepto ya caduco, que hace referencia al mundo artístico y literario de las clases educadas, gobernantes y adineradas (Firat y Venkatesh, 1995; Vilasuso, 2013).

6. "La publicidad podrá simular que es arte, pero nunca podrá disimular que no es publicidad, ya que la pertenencia al género la autoafirmación le es consustancial. No manifestarse como tal es característico de la propaganda, no de la publicidad" (Eguizábal, 1999: 321.

7. Ya desde la Roma Republicana se le atribuyó al arte una función accesoria, la de satisfacer la necesidad de reconocimiento social de ciertas clases sociales, sobre todo la de los libertos (Gómez-Vila, 1996: 421).

8. Considerado el mayor archivo de publicidad a nivel mundial, se actualiza de forma constante con la incorporación diaria de nuevos registros.

9. Con más de 120.000 obras pictóricas de todos los tiempos clasificadas por museos, por autores, por estilos y por temas, su web es una de las herramientas didácticas de pintura de referencia en España. La lista completa de autores sugeridos puede consultarse en http://pintura.aut.org/

10. Coloribus (http://es.coloribus.com/) clasifica los anuncios incluidos en su archivo en las siguientes categorías de publicidad: TV, impresa, al aire libre, ambiental, on line, viral, marketing directo, promoción, diseño, logotipos y radio.

11. Las nuevas fórmulas de la denominada publicidad no convencional o below the line pueden consultarse en Sánchez, J. y Pintado, T. (2010). Nuevas tendencias de la comunicación, Madrid: Editorial Esic 
12. Si la lingüística moderna nace con Saussure, su culminación teórico-formal se alcanza con Louis Hjelmslev, que en Prolegómenos para la teoría del lenguaje (1943) plantea una teoría cuyo fin era el desarrollo de una lingüística más general y con un enfoque más epistemológico.

13. El 8 de octubre de 2014 se presentó en el Museo ThyssenBornemisza de Madrid, Ferrero Golden Gallery, un nuevo surtido de especialidades Ferrero. Para Philippe Steyaert, director general de Ferrero Ibérica "Ferrero Golden Gallery reúne recetas exclusivas inspiradas en el mundo del arte que aúnan innovación, diseño y elegancia".

14. Juan Carlos Argüello, conocido como Muelle, fue el primer grafitero español. Creador de un estilo propio, el denominado "estilo flechero", comenzó a pintar en 1981 e influyó a toda la generación de grafiteros pioneros españoles (Reyes, 2012: 62).

15. La colección completa de etiquetas de Mouton Rothschild la integran un total de 67 etiquetas. Sea o no por el valor aportado por el arte en forma de etiquetas que acompaña el producto, lo cierto es que el Chateau Mouton-Rothschild 1945 es una de las botellas más caras de vino en el mundo, su precio se sitúa alrededor de los 23.000 dólares cada una.

16. La campaña comenzó a emitirse en 2013 y puede visualizarse en: https://www.youtube.com/watch?v=dlat-HdFpXE

17. Desde 1986 hasta 2004, Absolut Vodka ha desarrollado una colaboración con artistas de todo el mundo para la creación de diversas campañas gráficas para la marca hasta acumular un total de 850 obras de arte por encargo que se consideran parte del patrimonio cultural sueco y que se exhiben en el Spritmuseum en Estocolmo.

\section{Referencias bibliográficas}

Alberdi, M. J. (2002). “La nueva Era del licensing: Arte y publicidad. La influencia del "Pop Art” en la publicidad”. ¿Quién influye a quién? Control: la publicidad desde 1962, 41(484), 90-91. Alloza, A. (2002). La gestión estratégica de la marca. En Villafañe, J. (ed.), El estado de la publicidad y el corporate en España y Latinoamérica, pp. 47-71. Madrid: Pirámide.

Almela, R. (2004, marzo). “La imagen actual en la inserción del arte y la publicidad. Escuela de Jurisprudencia y Humanidades". Trabajo presentado en el III Simposium Arte y Publicidad en comunicación, Puebla de Zaragoza. Recuperado de http://www.criticarte.com/Page/file/ art2004/ArteyPublicidadPrint.html

Alpert, J. I. y Alpert, M. (1990). “Music Influences on Mood and Purchase Intentions”. Psychology \& Marketing, 7(2), 109-133.

Asenjo, I. (1998). El consumo cotidiano de la pintura. Transferencias de arte de Vanguardia a la vida cotidiana. Tesis Doctoral, Facultad de Bellas Artes, Universidad Complutense de Madrid, Madrid, España. Recuperada de http://eprints.ucm.es/tesis/19972000/H/1/H1013401.pdf

Bocigas, M. 0. (2011). “Una modalidad de marca incipiente: la marca Premium”. Revista ICADE de las Facultades de Derecho y Ciencias Económicas y Empresariales, 83-84, 45-68.

Boscán, J. P., y Mendoza, M. I. (2004). “Análisis semiótico de la publicidad de perfumes”. Opción, 20(45), 75-93. 
Brea, J. L. (2009). “Estética, Historia del Arte, Estudios Visuales". Estudios visuales, 3, 8-25.

Brihuega, J., Hernando, J., Ramírez, J. A. (2006). Historia del arte. Vol.4, El mundo contemporáneo. Madrid: Alianza.

Caro, A. (2012). "Introducción: Arte, Publicidad y Vida Cotidiana en el Espacio de Consumo". Pensar la Publicidad, 6, 147-150. doi:10.5209/rev_PEPU.2012.v6.40641

Cavalli, P. (2007). "El encuentro de dos mundos. Para diferenciarse las marcas recurren al arte". Revista Mercado. Recuperado el 27 de julio de 2016: http://patriciocavalli. blogspot.com.es/2007/09/el-encuentro-de-dos-mundos.html

Cifuentes, J. L. (2006). El signo lingüístico. Barcelona: Liceus, Servicios de Gestión.

Costa, J. (2012). “Construcción y gestión estratégica de la marca: modelo masterbrand". Revista Luciérnaga - Comunicación, 4(8), 20-25.

Cruz, R. (2001). “Como enseñar a través de los medios". Comunicar, 17, 166-169.

De Vicente, A. M. (2011). “Arte y Publicidad: Producción científica en universidades españolas (1998- 2010)". Revista Mediterránea de comunicación, 2, 209-220.

Del Pino, C., y Castelló, A. (2015). “La comunicación publicitaria se pone de moda: branded content y fashion films". Revista Mediterránea de Comunicación: Mediterranean Journal of Communication, 6(1), 105-128.

Díaz, D. (2010). “Arte-Publicidad, un binomio posible”. DDiseño. Recuperado el 31 de julio de 2016: http://www.arsfluentes.es/ddiseno/ddiseno-7/documento11.htm

Díaz-Soloaga, P. (2007). “Valores y estereotipos femeninos creados en la publicidad gráfica de las marcas de moda de lujo en España". Anàlisi: quaderns de comunicació i cultura, 35, 27-45.

Eco, U. (2009). Apocalípticos e integrados. Barcelona: Fabula Tusquets.

Eguizábal, R. (1999). “Arte menos publicidad: Reflexiones al margen. La dimensión artística de la publicidad". Publifilia, 2, 31-36.

Fernández, A. (1991). "La imagen del arte en publicidad: la apropiación del "aura”". Cuadernos de arte e iconografía, 4(8), 199-203.

Firat, A. F. \& Venkatesh, A. (1995). "Liberatory Postmodernism and the Re-enchantment of Consumption". Journal of Consumer Research, 22(3), 239-267.

Gómez-Vila, J. (1996). “La publicidad simbolizante: el arte en la publicidad impresa”. Actas del I Congreso de Innovación educativa, Vol. I, pp. 419-430. Santiago de Compostela (A Coruña): Tórculo Ediciones.

González, R. (1997). “Arte y Publicidad: acotaciones a un matrimonio irreverente, pero eficaz". Documentación social, 107, 53-82.

González, J. (1999). “Arte y publicidad. La estrategia de la sustitución”. Área 5inco Revista de comunicación audiovisual y publicitaria, 6, 87-116. Recuperado de http:// pendientedemigracion.ucm.es/centros/cont/descargas/documento3045.pdf

González, M. A. (2007). "Apuntes para pensar la publicidad como fenómeno estético". Recuperado el 27 de julio de 2016: http://www.magonzalezvalerio.com/artypub.pdf Gurrea, A. (1998). Introducción a la publicidad. Bilbao: Servicio editorial de la Universidad del País Vasco.

Gúzner, S. \& Fernández, A. (1991). “Arte y publicidad: esa extraña pareja”. Lápiz: Revista internacional del arte, 77, 60-68.

Hagtvedt, H. \& Patrick, V. M. (2008). "Art Infusion: The influence of visual art of the Perception and Evaluation of consumer products". Journal of Marketing Research, 
$\mathrm{XLV}, 379-389$

Hermoso, C. (2007). “Arte y publicidad, dos mundos que se entremezclan”. Ipmark: Información de publicidad y marketing, 684, 6-7.

Hernando, L. A. (1994). “Análisis semiótico del mensaje publicitario”. Actas del V Congreso internacional de la Asociación Española de Semiótica (A Coruña, 1992), Vol. II, pp. 513-523.

Hetsroni, A. \& Tukachinsky, R. H. (2005). "The Use of Fine Art in Advertising: A Survey of Creatives and Content Analysis of Advertisements". Journal of Current Issues and Research in Advertising, 27 (1), 93-107.

Hoffman, B. (2002). The Fine Art of Advertising. New York: Stewart, Tabori and Chang.

Ind, N. \& Saracco, C. (2009). ““'Branding” y arte”. Harvard Deusto Marketing y Ventas, 90, 46-51.

Jiménez, G. (2008). Estrategias de comunicación apoyadas en el uso del arte. Tesis Doctoral, Facultad de Comunicación, Universidad de Sevilla, Sevilla, España. Recuperada de: http:// www.doctorado.us.es/tesis-doctoral/repositorio-tesis/details/2/1854

Joy, A. \& Sherry, J. F. (2003). “Speaking of Art as Embodied Imagination: A Multisensory Approach to Understanding Aesthetic Experience". Journal of Consumer Research, 30, 259-282.

López, J. C. (2007). “Publicidad emocional: estrategias creativas”. Comunicación y hombre: revista interdisciplinar de ciencias de la comunicación y humanidades, 3, 143-146.

Llorente, C. \& García, M. L. (2016). “Street marketing: la ciudad como soporte interactivo para la comunicación de la marca". Actas IV Congreso Internacional Ciudades Creativas, Tomo II, pp. 6-22. Recuperado el 20 de noviembre de 2016: https://www.researchgate.net/ profile/Jose_Luis_Rubio-Tamayo/publication/299996130_ciudades_creativas_2016_tomo2/ links/5707c81e08ae2eb9421bd89f.pdf\#page=6

Muñoz, A. (2008). “El creciente peso de la marca: los directivos españoles se implican cada vez más en su gestión”. Dinero: inteligencia empresarial, 975, 46-47.

Nowlis, S. M., Mandel, N. y Brown McCabe, D. (2004). “The Effect of a Delay Between Choice and Consumption on Consumption Enjoyment". Journal of Consumer Research, 31, 502-510.

Pérez, J.C. (1998). “La publicidad como arte y el arte como publicidad”. Arte Individuo y Sociedad, 10, 181-191.

Ramos-Serrano, M. \& Pineda, A. (2009). “El advertainment y las transformaciones de los formatos en el ámbito publicitario: el caso de los fashion films". Tripodos, (2), 729-737.

Reguera, J. M. (2012). “Branding-Art o la integración de las marcas en el sistema del arte”. Recuperado el 28 de julio de 2016: http://www.puromarketing.com/3/12030/brandingintegracion-marcas-sistema-arte.html

Reguera, J. M. (2014). “Branding Art. La identidad de marca y el sistema del arte”. Recuperado el 28 de julio de 2016: http://javierreguera.es/branding-art-pdf/

Reyes, F. (2012). “Graffiti. ¿Arte o vandalismo?”. Pensar la Publicidad, 6, 53-70.

Ritzer, G. \& Jurgeson, N. (2010). “Production, Consumption, Prosumption The nature of capitalism in the age of the digital "prosumer'". Journal of consumer culture, 10(1), 13-36.

Rodríguez, E. (2014). “Ventajas del packaging”. Recuperado el 29 de julio de 2016:http://www. emprendedores.es/gestion/la-publicidad-silenciosa/ventajas-del-packaging

Rodríguez-Pina, G. (2016). ““Flashmob”: así son las acciones callejeras en grupo”. El País. Recuperado el 20 de noviembre de 2016: http://verne.elpais.com/verne/2016/08/03/articulo/1470215484_628222.html

Romero, C. A. (2014). “Lección de Lingüística. Consideraciones en torno de Ferdinand De Saussure: Asidero de la lingüística actual". Cuadernos de Lingüística Hispánica, 24, 13-24. 
Santesmanes, M., Merino, M. J., Sánchez, J. \& Pintado, T. (2009). Fundamentos de Marketing. Madrid: Ediciones Pirámide.

Sarmiento, F. (2011). “El arte como musa de la publicidad: el ámbito publicitario y su relación directa con el arte". Étapes: diseño y cultura visual, 13, 136-139.

Spangenberg, E. A., Crowley, A. E. y Henderson, P. W. (1996). "Improving the Store Environment: Do Olfactory Cues Affect Evaluations and Behaviors?". Journal of Marketing, 60, 67-80. doi: 10.2307/1251931

Spielvogel, J. J. (2010). Historia Universal. Civilización de occidente, Vol 2. México: Cengage learning.

Torreblanca, F. \& Lorente, P. (2012). "Marketing de guerrilla. Lo no convencional triunfa”. 3c Empresa: investigación y pensamiento crítico, 1(9), 2.

Vilasuso, R. (2013). La publicidad audiovisual: una forma de arte posmoderno. México: Editorial Lamm.

Villafañe, J. (2001). Dirección de Comunicación empresarial e institucional. Barcelona: Gestión 2000.

Walzer, A. (2010). "Arte y Publicidad. Elementos para debate". Aisthesis: Revista chilena de investigaciones estéticas, 47, 296-306.

\section{Sobre los autores:}

\section{Olga Heredero Díaz}

Graduada en Publicidad y RR.PP., personal investigador en formación del Grupo de Investigación UCM Consolidado “Arte, Arquitectura y Comunicación en la ciudad contemporánea” y coordinadora técnica de Arte y Ciudad. Revista de Investigación.

\section{Miguel Ángel Chaves Martín}

Doctor en Historia del Arte, Profesor Titular del Dpto. de Comunicación Audiovisual y Publicidad II (UCM), director del Grupo de Investigación UCM Consolidado “Arte, Arquitectura y Comunicación en la ciudad contemporánea”, vicepresidente de la Asociación Española de Críticos de Arte (AECA) y director de Arte y Ciudad. Revista de Investigación.

\section{Cómo citar:}

Heredero, O. y Chaves, M. (2016). "El arte en la publicidad. Tipologías del uso del arte visual en la comunicación comercial”. Comunicación y Medios, 25 (34), 96 - 113. 